\title{
OTR11 - DIVERSIDADE DE BACTÉRIAS ISOLADAS DE ÁREAS LIMPAS RELACIONADAS A ANÁliSES MICROBIOLÓgICAS DE PRODUTOS FARMACÊUTICOS
}

$\underline{\text { Lívia Maria Rubem Vidal }}^{2}$, João Flávio Carneiro Veras ${ }^{2}$, Mariana Oliveira Souza ${ }^{2}$, Elisa Martins Ladeira ${ }^{2}$, Paulo Victor Pereira Baio ${ }^{2,3}$, Verônica Viana Vieira ${ }^{1}$

1. Instituto Oswaldo Cruz, Fundação Oswaldo Cruz, Laboratório de Genética de Microrganismos, Rio de Janeiro, Brasil

2. Instituto Nacional de Controle de Qualidade em Saúde, Fundação Oswaldo Cruz, Setor de Identificação Bacteriana, Rio de Janeiro, Brasil

3. Laboratório Químico-Farmacêutico do Exército, Rio de Janeiro, Brasil

Objetivos: Este estudo teve como objetivo determinar a diversidade das bactérias provenientes de áreas limpas e avaliar a identificação bacteriana realizada com o sistema fenotípico automatizado VITEK2 (BioMerieux) e pela análise de sequências do gene 16S rRNA.

Metodologia: Um total de 208 amostras bacterianas oriundas de áreas limpas (ISO 5, 7 e 8) foram analisadas utilizando o VITEK2 e/ou análise de sequências do gene 16S rRNA. A metodologia molecular foi utilizada como referência para avaliar o VITEK2 quando ambas as metodologias puderam ser realizadas.

Resultados: As amostras bacterianas foram identificadas como pertencentes aos seguintes grupos: bastonetes Gram positivos irregulares (BGPI) (6,66\%), bastonetes Gram positivos formadores de endosporos (BGPE) (26,67\%), bastonetes Gram negativos (BGN) (8,33\%) e cocos Gram positivos fermentadores (CGPF) (23,33\%) e não fermentadores da glicose (CGPNF) (26,67\%). Segundo a identificação utilizando o VITEK2, os CGPF pertenceram a diferentes espécies de Staphylococcus (S. caprae, S. cohnii, S. epidermidis, S. equorum, S. haemolyticus, S. hominis, S. xylosus e S. warneri), Streptococcus parasanguinis e Granulicatella adjacens. A análise das sequências do gene 16S rRNA mostrou que 93\% das amostras de Staphylococcus foram identificadas corretamente. BGN pertenciam as espécies Sphingomonas paucimobilis, Pseudomonas oryzihabitans e ao grupo Moraxella. BGPE e CGPNF foram caracterizados utilizando o 
VITEK2 e análise da sequência do gene 16S rRNA. CGPNF apresentaram os seguintes gêneros: Arthrobacter, Barrientosiimonas, Brachybacterium, Janibacter, Kocuria, Macrococcus e Micrococcus. Estes gêneros foram identificados pelo VITEK2 como pertencentes ao gênero Micrococcus ou Kocuria ou não foram identificados. Entre os BGPE foram observados os seguintes gêneros: Bacillus, Cohnella, Paenibacillus, Terribacillus, Lysinibacillus, Oceanobacillus e Paenisporosarcina. Os gêneros mais encontrados foram Bacillus e Paenibacillus que são compostos por 168 e 144 espécies válidas descritas respectivamente. Esta diversidade justifica a dificuldade da identificação fenotípica dos BGPE. O VITEK2 apresentou 21,28\% de identificações equivocadas de BGPE e 34,04\% de amostras não identificadas. Os BGPI não puderam ser avaliadas pelo VITEK2 principalmente devido a característica de insolubilidade. A metodologia molecular mostrou a presença dos gêneros: Streptomyces, Microbacterium, Cellulomonas, Dermabacter, Corynebacterium, Agromyces, Nocardioides, Brevibacterium, Curtobacterium, Exiguobacterium, Rhodococcus, Dietzia e Gordonia.

Conclusão: Análises microbiológicas de produtos farmacêuticos estéreis devem ser realizadas em áreas limpas para garantir a qualidade e evitar resultados falso-positivos. A identificação de micro-organismos provenientes de áreas limpas é recomendada pela legislação e tem o intuito de promover investigações mais eficazes das possíveis fontes de contaminação microbiana e avaliar a eficácia dos procedimentos de limpeza. Este estudo mostrou que o VITEK2 não é indicado para a identificação de alguns grupos bacterianos encontrados em áreas limpas devido principalmente à ausência de perfis bioquímicos no banco de dados deste sistema. A ampla diversidade das bactérias isoladas de áreas limpas justifica a implantação de metodologias moleculares para a correta identificação de bactérias comumente encontradas neste ambiente. 